\title{
Contributors to Pediatric Obesity in Adolescence: More than just Energy Imbalance
}

\author{
Michelle Cardel*, Akilah Dulin-Keita and Krista Casazza
}

Department of Nutrition Sciences and Clinical Nutrition Research Center, University of Alabama at Birmingham, Birmingham, AL 35294-3360, USA

\begin{abstract}
Disentangling the etiology of pediatric obesity continues to challenge researchers. Due to rapid growth and development, changes in the hormonal milieu, increased autonomy in feeding practices and greater interactions with environmental factors, adolescence is a particularly important period for the determination of body composition trajectories and the relationship to current and future obesity outcomes. A plethora of studies have focused on excess energy consumption and physical inactivity as they relate to weight and fat gain in adolescence. Although these "Big Two" have an impact, the increasing trends in pediatric obesity are not accounted for solely by increased energy intake and decreased physical activity. Indeed, under similar conditions of energy balance, inter-individual variation in fat accumulation has been consistently noted. It is becoming more evident that additional factors may contribute independently and/or synergistically to the increase in obesity. Such factors include (but are not limited to) metabolic programming in utero and in early childhood, the hormonal environment, endocrine disruptors, parental feeding practices, and the built environment. Our objective, therefore, is to investigate possible factors, particularly in adolescence that contributes to the increase in pediatric obesity beyond "The Big Two".
\end{abstract}

Keywords: Obesity, metabolic programming, feeding practices, endocrine disruptors, intra-uterine environment, neighborhood, hormones.

\section{INTRODUCTION}

Although a certain level of weight gain is expected during adolescence, overweight and obesity occur during this transitional period at a higher rate compared to any other time during growth and development [1-3]. The proliferative capacity of adipose precursor cells from subcutaneous adipose tissue is very high just prior to full reproductive maturation in preparation for the elevated energy needs throughout reproductive growth and development [4]. The interactions of the neural, hormonal, metabolic and environmental factors during adolescence influence mechanisms that regulate tissue partitioning, thereby profoundly affecting current and future obesity-related phenotypes.

During adolescence, the neuroendocrine axes (hypothalamic pituitary adrenal (HPA) and hypothalamic pituitary gonadal (HPG)) intimately involved in maturation can have a large impact on metabolism, energy balance and body composition. These axes are not fully developed until midadolescence. Peripheral signals originating from adipose tissue, the gastrointestinal tract, the pancreas, and other tissues interact with indices of metabolic status (e.g. blood glucose concentration) integrating feedback to and from the brain. During maturation of the neuroendocrine axes and the integration of the peripheral signals to which these axes respond, the pubertal brain may be more sensitive to

*Address correspondence to this author at the Department of Nutrition Sciences, Webb 415, $15303^{\text {rd }}$ Ave S, University of Alabama at Birmingham, Birmingham, AL 35294-3360, USA; Tel: (205) 975-6226; Fax: (205) 934-7050; E-mail: mcardel@uab.edu 'stimuli' (e.g. sensory perceptions associated with food, satiety signals, metabolic cues) that can have profound consequences for future behavioral, biological and physiological functions. Given the roles of the HPA and HPG axes in energy homeostasis, small changes in the development of neuroendocrine pathways have repercussions for a wide range of basic physiological and metabolic functions that influence energy balance. The independent and interactive effects of incoming signals and outgoing products associated with these axes are key regulators of pubertal growth and development, with substantial physiologic and metabolic importance.

Metabolic signals influence and are influenced by food intake. Although food habits change over the life course, the base dietary habits are established in early adolescence [5, 6]. It has been suggested that by the age of 9 , a child's food selection habits become very similar to those of adulthood [7]. Parental influences shape these feeding practices and as a child becomes more autonomous, a variety of social pressures (both within and outside of the home) impact food choices and thereby influences metabolic signals. Taken together it has been suggested that the interaction of various factors encompass an obesogenic environment, which accounts for the mismatch in energy balance. Traditionally, the investigations of this obesogenic environment and its result on pediatric obesity has centered on "The Big Two", physical inactivity and excess consumption of energy-dense foods. This has led to a comprehensive body of literature of "The Big Two" but has dwarfed the focus and study of other notable mechanisms, which may be significant, factors influencing the obesity epidemic. Though we believe physi- 
cal activity and food intake are fundamentally important in elucidating obesity, they are not the only plausible mechanisms and study of other salient predictors need to be considered. In this review, we portray several pertinent factors that have been investigated for playing a role in rising obesity rates in children and adolescents.

\section{INTRA-UTERINE ENVIRONMENT}

The importance of fetal development for later health outcomes is illustrated in the concept of programming, i.e. the notion that during early ontogeny the developing fetus passes through critical periods of development, during which stimulus or insult can have a lasting or life-long effect on a phenotype [8]. Poor fetal growth, as a result of deficient maternal nutrition, has been shown to culminate in an increased risk for developing obesity and metabolic disease in later life $[9,10]$. These studies served as the foundation for the 'thrifty phenotype hypothesis,' that proposes when fetuses are exposed to a nutrient-poor environment, the fetus makes metabolic adaptations in order to increase chance of survival once birthed into an environment deplete in nutrients, making it an ideal adaptive mechanism if the fetus is born into a deprived environment. However, if the offspring is exposed to an environment where an excess of food becomes available, this early programming puts the child at risk for becoming obese.

Numerous studies have provided support for this hypothesis and show that maternal nutritional manipulation can result in a variety of phenotypes in offspring, many of which can lead to increased risk for diseases such as hypertension, obesity, diabetes, and metabolic syndrome [11-13]. In an animal model that investigated this relationship, sheep were used. Fetal sheep development closely resembles that of the human fetus because both species tend to increase body weight and adipose tissue deposition in late gestation [12]. The sheep were exposed in utero to either a nutrient-restricted or normal diet and all offspring were exposed to an obesogenic environment throughout adolescence. This resulted in similar degrees of juvenile obesity, with both groups being about $45-50 \%$ heavier than lean sheep of the same age [14]. Interestingly, the offspring that had been exposed to a nutrient-restricted diet had increased adipose tissue dysregulation and altered insulin signaling [14]. In humans, individuals exposed in utero to a deprived nutritional environment not only have increased total adipose tissue but they tend to store the excess fat centrally, which is a risk factor for cardiovascular disease and its life-shortening sequelae [15]. This was demonstrated by Labayen et al. who found birth weight was inversely associated with adiposity in adolescents [16]. In a prospective study that looked at intrapair differences between the heaviest and lightest twin at birth, they found that a deprived intra-uterine environment, as measured by birth weight, was associated with more subcutaneous and abdominal fat and less lean body mass in adolescence and young adulthood [17]. However, there is a U-shaped curve in regard to infant birth weight and obesity risk. Large-for-gestational-age infants seem to have similar adverse consequences in adolescence as those who have impaired fetal growth, as maternal BMI positively influences child birth weight. In a recent meta-analysis, the prevalence of fetal macrosomia was $13.3 \%$ for obese women compared with $8.3 \%$ for the normal weight control group [18], with offspring of mothers with a higher BMI or gestational diabetes being larger at birth [19]. The significant relationship between higher BMI and obesity seen in people across the lifespan who were heavier at birth suggests that fetal life is a critical window for programming body composition in later life [20]. In a cohort study of over 14,000 adolescents, a $1 \mathrm{~kg}$ increment in birth weight in full-term infants was associated with an approximately $50 \%$ increase in the risk of being overweight during adolescence [21]. Even when adjusted for maternal BMI, the increase in risk remained considerably elevated at $30 \%$. Interestingly, both paternal and maternal adiposity are correlated with a higher birth weight of the offspring. However, the relationship is much stronger for the mother compared with the father [22], suggesting that the intrauterine environment plays a more important role in the later development of obesity. Though these are observational studies and cannot imply causation, there is significant evidence that maternal overweight or overfeeding in utero can lead to adverse health-related phenotypes.

Additionally, intrauterine exposure to maternal diabetes, in the form of type 2 diabetes or gestational diabetes can have lasting effects on adolescence. Offspring of diabetic mothers have increased risk for fetal macrosomia and obesity, indicating that long-term postnatal development may also be modified by metabolic experiences in utero. Maternal gestational diabetes mellitus and type 2 diabetes increase the concentrations of glucose in maternal blood and is delivered to the fetus, resulting in fetal hyperinsulinemia and increased production of other growth factors [23], which can lead to macrosomia and increased adiposity. Supporting this theory, a prospective study done by Silverman et al. found that children born of diabetic mothers were more likely to have macrosomia at birth were significantly heavier with a mean BMI of 24.6 during adolescence compared to a BMI of 20.9 in control subjects [24]. The children born from diabetic mothers were also more likely to have impaired glucose tolerance, possibly due to exposure to elevated amniotic fluid insulin levels seen in diabetic mothers [24]. The prevalence of maternal obesity can compound these effects [13]. However, the effects of intrauterine exposure can be confounded by genetic factors. In order to control for these genetic contributions, one study compared adolescent sibling pairs born prior to or after the mother was diagnosed with diabetes, and found that the siblings born after the mother was diagnosed with diabetes had a mean BMI that was $2.6 \mathrm{~kg} / \mathrm{m}^{2}$ higher than offspring of non-diabetic pregnancies [25]. Yet, there were no significant differences in BMI between sibling pairs born prior to and after the father was diagnosed with diabetes. This provides further evidence that intrauterine exposure to metabolic disease can increase the risk of obesity in offspring, beyond what is attributable to genetic factors.

Thus, it seems that there is a U-shaped relationship between birth weight and obesity-related phenotypes such that offspring from both extremes of the maternal nutrition spectrum are susceptible to obesity, central adiposity and its resulting long-term health risks. Intrauterine exposure to maternal diabetes also leads to higher risk for the develop- 
ment of obesity in adolescents. This provides further support for the 'thrifty gene hypothesis' that during critical periods of development in utero, stimulus or insult in the form of maternal overfeeding or malnutrition and maternal diabetes, can have lasting or life-long effects on a phenotype.

\section{HORMONAL ENVIRONMENT}

The onset of puberty is characterized by changes in the HPG axis resulting in an increase in frequency and amplitude of the gonadotropin releasing hormone $(\mathrm{GnRH})$ 'pulse generator' and resultant surge in reproductive hormone secretion. The response to increased reproductive hormone production is activation of the gonads. Although the exact mechanism remains unclear, it appears that insulin exhibits a stimulatory effect on gonadal cells augmenting production of reproductive hormones as well as tissue partitioning signals based on the body's energy reserves. Insulin may also act on the pituitary to increase the sensitivity of gonadotropins to GnRH [26]. Together, the interactions of reproductive and metabolic hormones contribute to body weight control and when aberrant, play a role in the pathogenesis of obesity.

Metabolic hormones (e.g. leptin and insulin), in addition to reproductive hormones, are linked in a positive feedback cycle. Insulin facilitates glucose uptake and inhibits lipolysis triggering increased energy storage. In addition, transient insulin resistance associated with puberty augments these mechanisms placing adolescents (particularly females who in general are more insulin resistant) at a much higher risk for weight gain and fat mass accrual. Leptin not only communicates the status of energy availability to the hypothalamus but also plays a role in the progression and initiation of puberty [1]. Increased leptin is permissive to the GnRH pulse generator, increasing reproductive hormone release. Further, the selective physiologic pressures associated with female reproductive capacity place females at a greater risk for excess fat mass accrual in adolescence. Greater fat accumulation increases secretion of leptin and estradiol and further exacerbates disturbances in insulin metabolism. Increased adiposity drives further leptin release. Cumulatively, in girls, elevated insulin interferes with leptin signaling decreasing leptin sensitivity and increasing estradiol, weight gain and food intake [27]. In boys, the literature indicating a relationship between these feedback mechanisms and pubertal fat mass accumulation is not quite as clear as in girls. Boys are less often studied [28] and the mechanistic link between reproductive maturation and obesity is uncertain. Nevertheless, some studies suggest that the obesityrelated phenotype delays reproductive maturation and this delayed pubertal onset leads to disturbances in body tissue partitioning [29, 30]. Delayed onset of the testosterone surge associated with the male pubertal transition could potentially result in less lean tissue accrual, thus partitioning resources towards fat $[31,32]$. Conversely, other studies report earlier reproductive maturation is related to rapid weight gain in early maturing boys leading to a higher fat mass index in later adolescence [33-35]. Though there is a dearth of information demonstrating the mechanistic impact of pubertal metabolic hormones on fat mass gain in boys, just as in girls, it is clear perturbations in the hormonal axes in boys alter energy balance and tissue partitioning.
During puberty, another key factor regulating tissue partitioning is insulin-like growth factor -I (IGF-I). IGF-I contributes to the mechanisms involved in reproductive hormone release affecting sexual maturation and inducing a growth spurt. As the GnRH pulse generator advances gonadal development, increased reproductive hormone secretion leads to increased release of growth hormone $(\mathrm{GH})$ and IGFI. Due to a marked increase in growth hormone $(\mathrm{GH})$ secretion as well as secretion of the gonadotropins [36], IGF-I levels normally peak during puberty. $\mathrm{GH}$, secreted into the general circulation, stimulates the synthesis and secretion of IGF-I in the liver and other organs, mediating many of the growth effects of GH. IGF-I also acts as an operant in a negative feedback loop by actions at the hypothalamus and pituitary. Despite this negative feedback relationship, both $\mathrm{GH}$ and IGF-I are elevated during puberty [36]. The increased secretion of $\mathrm{GH}$ and reproductive hormones, transient reduction in insulin sensitivity, and resultant elevation in circulating insulin contribute to the pubertal increase in IGFI. As such, puberty has been suggested as a sensitive period for the programming of adult IGF-I levels.

Circulating IGF-I concentrations during puberty are approximately two to three times greater than during adulthood and increase with pubertal status, with the most significant increase taking place at mid-puberty [37]. Juul et al. [38] investigated the relationship between IGFs and their binding proteins in children, finding significant variation throughout the pubertal transition for IGF-I and IGFBP-3. Maximal levels of both were seen nearly two years later than peak height velocity, as well as increasing IGF-I levels in the years after peak height velocity as growth velocity decreased, supporting the relationship between the IGF system and height. Findings also suggest that IGFBP-3 increases with prepubertal maturation, but significantly decreases throughout final stages of puberty [39-41]. The IGF1 :IGFBP-3 molar ratio (a reflection of free, biologically active IGF-I) also increases in puberty, suggesting differential regulation during this period. IGFBP-1 decreases with the lowest levels in puberty, likely as a result of alterations in insulin dynamics and/or alterations in the reproductive hormonal milieu. Together reproductive hormones, $\mathrm{GH}$, and IGF-1 suppress insulin sensitivity, while increasing insulin secretion and influencing body composition [42].

Just as reproductive maturation differs between males and females, so too do IGF levels; with girls having higher IGF-I than males [43]. Accordingly, the growth spurt for males accelerates slower, begins later, and lasts longer. In females, marked alterations in hormonal activity (mostly pituitary and gonadal hormones) are due to the dramatic stimulation of the HPG axis. Lofqvist et al. showed that in mid-puberty there is a difference in the relationship of age and IGF-I between boys and girls, with a positive age effect in boys and a fairly constant age effect in girls [44]. Further, IGF-I values were higher for mid-pubertal girls than boys. These results are in agreement with the observation that girls have peak height velocity, along with elevation of serum IGF-I, earlier than boys. Interestingly, girls have significantly higher IGFBP-3 levels than boys throughout puberty [45]. There appears to be a reversal of this sexual dimorphism following reproductive maturation [46]. Notwithstanding, an interactive effect of the IGF axis and reproduc- 
tive maturity is evident; the physiological implications of the relationship, however, are not clear.

Variations in the IGF axis noted prior to puberty but not consistently observed after reproductive maturation may indicate that IGF-I levels in puberty serve as a "biological switch" affecting gene expression that permanently alters the physiology of the individual's response to various stimuli later in life. It is also plausible that pubertal IGF-I levels and variations in the IGF axis may be one of the physiological pathways that increase risk of chronic disease later in life. It has been proposed that physiologic and metabolic programming that occurs during puberty may initiate events that lead to the development of these diseases over the life course.

\section{Stress and the Adolescent Brain}

In addition to the influence of the HPG axis, recently the HPA axis has also been implicated in the pathogenesis of obesity due to its influence on body fat partitioning and feeding behavior [47]. The HPA is involved in the stress response via cortisol secretion and undergoes profound changes during adolescence that may contribute to an individual's vulnerability to weight gain. However, the HPA axis affects energy balance in different ways and with different underlying mechanisms. For example, in adipose tissue, cortisol promotes the differentiation of pre-adipocytes to mature adipocytes and increases lipoprotein lipase activity, plausibly facilitating weight gain [48]. Cortisol is associated with decreased insulin sensitivity and a compensatory increase in insulin that may affect food intake [49]. The HPA axis also interferes with leptin release and may reduce the efficacy of leptin to suppress food intake [47].

Though the cascade of events by which stimulation of the HPA axis leads to the secretion of cortisol has been identified [47], there is a dearth of evidence regarding the response of the adolescent brain to stress. A relationship between cortisol secretion and obesity is gaining support, and stressors experienced during puberty can have longlasting and profound consequences on physiology and behavior. The adolescent brain may, in fact, be more sensitive to cortisol and/or experience differential exposure to cortisol than the fully developed adult brain, such that unlike the reversibility of the effect of stressors in the adult, pubertal stress may lead to loss of developmental plasticity with possibly permanent effects. Though much of the food intake data associating the stress response to macronutrients has been compiled in animals, it is plausible that the glucocorticoid response may underlie the preference for certain macronutrients in humans after stress (high fat and carbohydrate/sugar). Studies in rodents have demonstrated a more prolonged acute stress response in juveniles relative to adults and that chronic exposure to such stress during adolescence is accompanied by alterations in HPA axis habituation [49]. These studies suggest that experience-dependent plasticity of the HPA axis is manifested in pubertal development. It is imperative to understand the influence of stress and stress hormones on neuronal circuitry and whether effects on the structure and function of the brain occurring during puberty are transient or permanent.

\section{ENDOCRINE DISRUPTORS}

Although relative importance in terms of obesity-related phenotypes is unknown, chemicals that have been created in an effort to improve efficiency of agriculture and industry, as well as enhance pharmaceutical and beauty products have been suggested to be among such contributors to the obesity epidemic. The vast majority of these chemicals are considered harmless; however, recent investigations suggest that some may be regarded as endocrine disrupting compounds (EDCs), particularly in childhood [50]; that is, compounds which through exposure interfere with the hormonal biosynthesis and homeostatic systems associated with growth, development and reproduction [50]. These EDCs can either speed up or delay puberty due to interruption in normal hormonal activity. The group of chemicals comprising EDCs is heterogeneous and includes a number of substances and by-products; e.g., bisphenol A (BPA), phthalates, diethylstilbestrol (DES), polychlorinated biphenyls (PCBs), polybrominated biphenyls (PBBs). They can be found in food, air, water, soil and common household items such as clear containers (e.g. water bottles) and cling wraps [51]. Hormones play a critical role in development, and disruption of the endocrine system by these various EDCs may have profound effects on obesity-related phenotypes during adolescence [50].

Due to the rapid change in the hormonal milieu and body tissue partitioning associated with puberty, it is highly plausible that exposure to EDCs during this period contributes to alterations in adipocyte differentiation and energy storage. During the reproductive maturation process, sex-hormones are synthesized in peripheral adipose tissue before the gonads begin to function. Additionally, exposure to EDCs in utero can alter the age of onset of puberty of the offspring [52]. Research has consistently indicated a link between early onset of puberty and later obesity. Experimental literature strongly supports an association between EDCs and decreased age of pubertal onset $[53,54]$. Further, reproductive hormones in conjunction with hormones associated with growth (e.g. GH, IGF-I) influence lipid mobilization [54]. Interestingly, imbalances in the relationship between reproductive and growth hormones commonly observed in genetic, clinical and physiological conditions associated with obesity can be induced by the introduction of EDCs. Research in rodent models has uncovered disturbances in energy metabolism pathways mediated by EDCs that result in adipogenesis [55-57]. Further, several peptidnergic signals emanating from the hypothalamus and other brain regions are influenced by alterations in receptor signaling making them potential transcriptional targets for EDCs [57]. As such, the possibility that EDCs exert obesogenic effects on the HPA and HPG axis during puberty is highly plausible. EDCs have also been identified as agonistic for PPAR $\alpha$ and $\lambda$ resulting in the stimulation of adipocyte proliferation [58]. Metabolites of PPAR agonists provide a possible route for initiating a pro-adipogenic response. The mechanistic interference by EDCs on the body tissue partitioning through a variety of pathways during pubertal growth and development may exert cumulative metabolic and physiologic effects that occur throughout the pubertal transition. 
Each person has unique exposure to a variety of known and unknown EDCs. Although still controversial, it has been reported that the maximum fat cell number is attained by late adolescence and that obese young adults possess approximately $30 \%$ more total fat cells than their lean counterparts [59]. This finding implies that fat accumulation patterns are determined relatively early in life. Individual differences in metabolism and body composition will create considerable variability in the persistence and degradation of EDCs. Further, the effects of EDCs may not be detectable until years after the initial exposure in the individual and may have effects on the offspring. Although the latency between exposure and occurrence of obesity-related phenotypes creates a challenge when attempting to establish a relationship, taken together, the pubertal transition poses a unique environment in which exposures to EDCs may have lifelong implications. This is particularly concerning as endocrine disruptors have increased in foods and beverages [60].

The link between EDCs and disease (e.g. cancer) was introduced several decades ago and contemporary studies suggest the association extends to obesity. Since the establishment of the obesity link, numerous pathways in the progression towards excessive fat accumulation have been suggested. The most commonly proposed mechanisms by which EDCs are thought to act are: by direct binding to the estrogen receptor, hypothalamic dysregulation and/or activation of peroxisome proliferator-activated receptors (PPARs) [50]. Considering the ubiquitous nature and potential contribution to health of such exposures, further research is merited.

\section{PARENTAL FEEDING PRACTICES}

Feeding practices were developed in humans as survival responses to environmental barriers and threats (predominantly food scarcity and infectious diseases) and have been passed down generationally [61]. The threat of food scarcity led parents to feed their children often, many times using forced feeding and persuasion, in order to encourage the children to eat as much as possible during times of food availability. This was done to ensure that the children would have enough stored energy, in order to withstand periods of food scarcity. However, in the present-day environment the excess of energy dense foods is readily available, convenient, and affordable, these parental feeding practices can lead to adverse metabolic and physiologic effects, that mediate adolescent weight/fat gain.

The study of the relationships among parental feeding practices, child eating behaviors, and child weight status has yielded useful information regarding factors that are important modifiable predictors of adolescent obesity. Engaging in unhealthy parental feeding practices, such as parental restriction, can lead to adolescent overweight. "Restriction" is defined by limiting a child's intake of "unhealthy" or calorie-dense foods, particularly at snack time, leads to overfeeding and weight gain [62-66]. For example, studies have shown that maternal monitoring of child's food intake, restriction of foods, and concern for their child's weight may in fact be counterproductive ensuing in eating in overindulgence when restricted foods become available to the child [62]. In girls, higher restriction led to eating without hunger by age seven in girls and more severe restriction related to greater fat mass [64]. Eating in the absence of hunger is seen more often in children and adolescents who are overweight $[67,68]$. Laboratory studies have indicated that adolescents have been observed in laboratory settings, eating large amounts of palatable food in the absence of hunger after a meal, and this excess energy intake is positively related to child weight [68].

Thus, restricting and controlling a child or adolescent's eating and weight in order to prevent obesity may be counterproductive, creating the problem it was intended to prevent by facilitating the dysregulation of energy balance. There is significant disjoint between parental perceptions of their feeding practices and the expected health outcomes for the child. A significant percentage of parents report that restricting a particular food from a child will actually decrease the child's preference or liking of that food [69], however, research shows that children's preferences for restricted foods are increases when the food is restricted from them or used as a reward [70]. The foods that are restricted by parents tend to be more unhealthy foods that are highly palatable, high in fat, sugar, and energy. Restrictive feeding practices can potentially send mixed signals to adolescents because they are restricted from consuming these unhealthy foods but are often encouraged and coerced to eat ample amounts of foods that parents believe to be healthy, such as fruits and vegetables. In turn, adolescents categorize foods as healthy or unhealthy which can result in the adolescent's self-restriction of foods that they perceive as unhealthy. This can be detrimental to adolescent weight status as such restrictive behavior coupled with dieting have been related to eating pathology $[71,72]$ including overeating and binge eating [73]. Adolescent's restraint scores have also been related to weight status and disordered eating styles [72]. Mechanistically, it has been suggested that restrained eating may lead to episodes of binge eating through the increased attractiveness of restricted foods and weakened satiety cues. Thus, parents may have the intention of promoting a healthy diet and preventing obesity, however research shows that these well intentioned behaviors can result in dysregulation of energy intake and lead to eating in the absence of hunger, dieting, overeating, and obesity [64, 73].

Unlike restriction, "pressure to eat" is associated with lower weight in children and adolescents [64, 66], and has been associated with lower fruit and vegetable intake and picky eating in children [74]. "Pressure to eat" is defined as parents' pressuring the child to eat nutrient-dense foods that are considered "healthy," particularly at mealtimes. In an experimental setting where children were pressured to finish their meal, Galloway et al found that children consumed significantly more food when they were not pressured to eat and made significantly fewer negative comments [75]. Additionally, those who were pressured to eat at home by their parents had significantly lower BMI scores when compared to those children who were not pressured to eat [75]. This suggests that "pressure to eat" is not effective in promoting intake of food and can actually result in an aversion to the pressured food. The consequences of these eating practices experienced as children track into adolescence and adulthood. Supporting this notion, retrospective data found that adolescents and young adults reported dislike 
of and refusal to eat foods that they had been pressured to eat as children [76]. The data reveal that pressuring food intake is not an effective strategy for promoting a "healthier diet" and can be counterproductive resulting in lasting aversion to the foods they are coerced into eating.

These feeding practices vary by culture and can be influenced by a child's age, gender, weight status, and eating behavior [62]. However, these reviews may be limited due to the majority of studies being conducted in white motherchild dyads from middle and upper class income levels. We know little about how these relationships relate to lowincome or minority populations, who are known to be at higher risk for obesity [77]. There is a need for research to investigate how socioeconomic status (SES) and ethnicity may affect body fatness outcomes in relation to parental feeding practices with a multi-ethnic sample.

\section{THE BUILT ENVIRONMENT}

Neighborhood factors such as the built and social environments have been associated with obesity outcomes among subsets of the youth population [78]. The mechanisms for these environmental effects are two-fold and include 1) reduced access to health promoting resources within neighborhoods such as quality grocery stores, sidewalks, and recreational facilities and 2) neighborhood social factors such as fear of crime, perceived victimization risk, reduced neighborhood social ties, and psychosocial stressors. [79-81] Youth who reside in urban, low-income, and rural neighborhoods are particularly vulnerable and may have increased risks for obesity and the related comorbidities [8287].

Assessments at the neighborhood level have identified geospatial differences in access to grocery stores, supermarket chains, differential dietary patterns and obesity risks $[88,89]$. The presence of large-scale supermarkets and grocery stores is thought to afford some protection against unhealthy dietary behavior and child overweight status. However, youth in low income neighborhoods have reduced access to healthy food environments where fresh fruits, vegetables, whole grains, and fish are readily available [9092]. The work of Powell and colleagues found that supermarket chains within neighborhoods significantly affected child weight status [93]. Additionally, the presence of an additional supermarket per 10,000 capita was associated with a reduction in the prevalence of overweight by almost 1 percentage point. Conversely, each additional convenience store per 10,000 capita increased overweight by .15 percentage points [94]. The presence of fast food restaurants located near neighborhood schools is also obesogenic for adolescents [95]. Additional studies support these findings and suggest that reduced availability to quality foods contributes to higher adolescent BMI $[96,97]$. The increased density of unhealthy community food resources may lead to neighborhood collective lifestyles that promote unhealthy dietary behaviors and increase the risks for overweight/ obesity among youth [94, 98-100].

The role of the neighborhood environment as it relates to physical activity also significantly affects obesity risks for youth. Significant factors such as access to recreational facilities, the presence of sidewalks, and the perception of neighborhood safety can influence participation in physical activity within the neighborhood [101]. In impoverished areas, health promoting infrastructures such as recreational facilities or parks are often underutilized whether due to safety concerns or absence, and the absence of these healthpromoting behaviors can promote inactivity among neighborhood residents [102]. When added into a model assessing the effects of neighborhood factors on vigorous activity among youth, a study found that perceptions of the safety of neighborhood facilities contributed an additional 13 percent of the variance explained in physical activity patterns [103]. Evenson and colleagues assessed the relationship between neighborhood factors and BMI for adolescent girls [104]. The findings from this work indicate that neighborhood factors such as reduced crime, seeing their peers playing outside, and the availability of recreational facilities are associated with lower BMI. Although the influence of neighborhood factors may be minimal, the effects appeared to be important and may have operated to protect adolescent girls from increased obesity risk [104].

While research suggests that low neighborhood socioeconomic status, social, and physical characteristics are associated with higher BMI among children [105-108], other studies have shown that neighborhood factors may not play a role in predicting childhood obesity [109, 110]. Although informative, these studies utilize BMI as a surrogate for obesity status, which may limit the strength of these findings, particularly among racial/ethnic minorities. New directions that assess the relationship of neighborhood factors and adiposity levels among children should include more robust body composition methods.

\section{DISCUSSION}

The five putative contributors to pediatric obesity that have been presented in this article are consistent among animal and human models and epidemiological studies. However, we are not claiming that the proposed explanations are unquestionably predictive factors in childhood obesity, but that they are possible contributors that deserve further study and review. It is important to note that this was not an exhaustive review of all possible contributors. Due to much of the literature being dedicated to the consumption of energy dense foods, sugar-sweetened beverages, and sedentary behavior and its influences on weight in children, it was pertinent to bring to light other research that could also identify salient contributors. Though we believe the "Big Two" are important, they have not provided us with long-term results in reducing overweight, and have overshadowed other persuasive determinants of childhood obesity.

The lasting effects of fetal programming in utero are seen when the fetus is exposed to maternal over/under nutrition, maternal overweight and/or diabetes, resulting in increased risk for developing obesity and metabolic disease in later life $[9,10]$. Intrauterine nutrient exposure can explain some of the variance in obesity for at risk offspring alluding to the fact that during critical periods of development in utero, stimulus or insult in the form of maternal overweight or overfeeding can have lasting effects on a phenotype in adolescence. Thus, it seems that there is a U-shaped relationship 
between birth weight and obesity-related phenotypes in offspring from both extremes of the maternal nutrition spectrum. These infants as adolescents are susceptible to obesity, central adiposity and its resulting sequalae. Intrauterine exposure to maternal diabetes is also related to a higher risk for the development of obesity and type 2 diabetes in adolescents. This provides further support for the 'thrifty gene hypothesis' that during critical periods of development in utero, stimulus or insult in the form of maternal overfeeding or malnutrition and maternal diabetes, can have lasting or life-long effects on a phenotype. However, the exact mechanisms underlying this phenomenon in adolescents are unclear and carefully designed longitudinal studies need to be performed.

A variety of signals emanating from the HPA and HPG axes can act as 'endogenous functional teratogens' by malprogramming the neuroendocrine system [111] leading to developmental disturbances in insulin signaling, satiety, body composition and energy balance. Metabolic signals within the immature hypothalamus (via behavioral, environmental or physiological cues), followed by fluctuations in the reproductive hormonal milieu and aberrations in tissue partitioning could plausibly lead to lifelong dysfunction of systems regulating metabolism and body weight. The extent to which adaptations during adolescence are attributable to permanent alterations in physiology remains a plausible pathway in unraveling the etiology of pediatric obesity.

Recent studies suggest that endocrine disrupting compounds can interfere with the hormonal biosynthesis and homeostatic systems associated with growth, development and reproduction, particularly in childhood and adolescence [50]. Because of the critical role that hormones play in controlling development, disruption of the endocrine system may have profound effects during childhood and adolescence and it is highly plausible that exposure to EDCs during this period contributes to alterations in adipocyte differentiation and energy storage. This is particularly concerning as endocrine disruptors have increased in common household products and in the food market [60]. Considering the ubiquitous nature and potential contribution to health of such exposures, further research is merited.

Feeding practices, evolutionarily developed in humans as survival responses to the threat of food scarcity, are often incompatible with the current environment [61]. The increased prevalence of pediatric obesity in the last thirty years leads many to believe that the obesogenic environment accounts for the mismatch in energy balance. Though often well-intentioned, parental feeding practices, particularly restrictive feeding practices and pressure to eat, can reduce a child's ability to self regulate energy intake and can lead to overfeeding, dieting, picky-eating, and weight gain in adolescence. A parent's restriction of foods may in fact be counterproductive by inadvertently increasing the liking or preference of the restricted food and by endangering selfregulation mechanisms of energy consumption and eventually leading to a higher energy intake when restricted foods become available to them [62]. These feeding practices vary by culture and can be influenced by a child's age, sex, weight status, and eating behavior. However, in today's environment where an excess of energy dense foods is readily available, convenient, and affordable, exhibiting these parental feeding practices can lead to adverse effects, and may be contributing to the increased prevalence of overweight in adolescents.

Neighborhood factors such as the built and social environments have been associated with obesity-related phenotypes in adolescents [78]. Reduced access to health promoting resources within neighborhoods (i.e. quality grocery stores, sidewalks, and recreational facilities) and neighborhood social factors (i.e. fear of crime, perceived victimization risk, reduced neighborhood social ties, and psychosocial stressors) have been associated with increased prevalence of obesity in the pediatric population $[80,112,113]$. Youth who reside in urban, low-income, and rural neighborhoods are particularly susceptible and may have augmented risks for obesity.

Conventionally, investigations looking at factors influencing obesity in adolescents have centered on "The Big Two," physical inactivity and excess consumption of energy-dense foods, leading to a large body of literature on "The Big Two." This has overshadowed the study of other notable mechanisms which may be significant factors influencing the obesity epidemic and we present some of these possible predictors in this review. Though we believe physical activity and food intake are fundamentally important in elucidating obesity, we consider the salient factors outlined in this review to be plausible contributors as well.

\section{FINANCIAL SUPPORT}

R01-DK067426, R25 CA47888, Cancer Prevention and Control Training Program grant, funded by the National Cancer Institute, National Institutes of Health.

\section{DISCLAIMER}

This research manuscript and the data presented in this paper have not previously been published, either in whole or in part, and no similar paper is in press or under review elsewhere. The work is not and will not be submitted to any other journal while under consideration by The Open Obesity Journal. Additionally, none of the authors have potential conflicts of interest that could raise questions about a paper's credibility if disclosed later. Further, each author listed on the manuscript has seen and approved the submission of this version of the manuscript and takes full responsibility for the manuscript.

\section{REFERENCE}

[1] Jasik CB, Lustig RH. Adolescent obesity and puberty: the "perfect storm". Ann N Y Acad Sci 2008; 1135: 265-79.

[2] Kimm SY, Barton BA, Obarzanek E, et al. Racial divergence in adiposity during adolescence: The NHLBI Growth and Health Study. Pediatrics 2001; 107: E34.

[3] Thompson AM, Baxter-Jones AD, Mirwald RL, Bailey DA. Comparison of physical activity in male and female children: does maturation matter? Med Sci Sports Exerc 2003; 35: 1684-90.

[4] Ailhaud G, Massiera F, Weill P, Legrand P, Alessandri JM, Guesnet P. Temporal changes in dietary fats: role of $n-6$ polyunsaturated fatty acids in excessive adipose tissue development and relationship to obesity. Prog Lipid Res 2006; 45: 203-36.

[5] McNaughton SA, Mishra GD, Stephen AM, Wadsworth ME. Dietary patterns throughout adult life are associated with body 
mass index, waist circumference, blood pressure, and red cell folate. J Nutr 2007; 137: 99-105.

[6] Northstone K, Emmett PM. Are dietary patterns stable throughout early and mid-childhood? A birth cohort study. Br J Nutr 2008; 100: 1069-76.

[7] Northstone K, Emmett PM. Are dietary patterns stable throughout early and mid-childhood? A birth cohort study. Br J Nutr 2008; 100: 1069-76.

[8] A Lucas. Programming by early nutrition in man. Ciba Foundation Symposium 1991; 156: 38-55.

[9] Hales CN, Barker DJP, Clark PM, et al. Fetal and infant growth and impaired glucose tolerance at age 64. BMJ 1991; 303: 1019-22.

[10] Barker DJP, Hales CN, Fall CH, Osmond C, Phipps K, Clark PM. Type 2 (non-insulin-dependent) diabetes mellitus, hypertension and hyperlipidaemia (syndrome $\mathrm{X}$ ): relation to reduced fetal growth. Diabetologia 1993; 36: 62-7.

[11] Mcmillen IC, Robinson JS. Developmental origins of the metabolic syndrome: prediction, plasticity, and programming. Physiol Rev 2005; 85: 571-633.

[12] Symonds ME, Sebert SP, Hyatt MA, Budge H. Nutritional programming of the metabolic syndrome. Nat Rev Endocrinol 2009; advance online publication.

[13] Yariv Yogev, Gerard H.A.Visser. Obesity, gestational diabetes and pregnancy outcome. Semin Fetal Neonat Med 2009; 14: 77-84.

[14] Sharkey D, Gardner DS, Fainberg HP, et al. Maternal nutrient restriction during pregnancy differentially alters the unfolded protein response in adipose and renal tissue of obese juvenile offspring. FASEB J 2009; 23: 1314-24.

[15] Kensara OA, Wootton SA, Phillips DI, Patel M, Jackson AA, Elia M. Hertfordshire study group. fetal programming of body composition: relation between birth weight and body composition measured with dual-energy X-ray absorptiometry and anthropometric methods in older Englishmen. Am J Clin Nutr 2005; 82: 980-7.

[16] Labayen I, Moreno LA, Blay MG, et al. Early programming of body composition and fat distribution in adolescents. J Nutr 2006; 136: 147-52.

[17] Loos RF, Beunen G, Fagard R, Derom C, Vlietinck R. Birth weight and body composition in young adult men-a prospective study. Int J Obesity 2001; 25: 1537-45.

[18] Chu SY, Kim SY, Lau J, et al. Maternal obesity and risk of stillbirth: a metaanalysis. Am J Obstet Gynecol 2007; 197: 223-8.

[19] Ehrenberg HM, Mercer BM, Catalano PM. The influence of obesity and diabetes on the prevalence of macrosomia. Am J Obstet Gynecol 2004; 191: 964-8.

[20] Sayer AA, Syddall HE, Dennison EM, et al. Birth weight, weight at $1 \mathrm{y}$ of age, and body composition in older men: findings from the Hertfordshire Cohort Study. Am J Clin Nutr 2004; 80: 199-203.

[21] Gillman MW, Rifas-Siman SL, Berkley CS, et al. Maternal gestational diabetes, and adolescent obesity. Pediatrics 2003; 111: e221-6.

[22] Parsons TJ, Power C, Manor O. Fetal and early life growth and body mass index from birth to early adulthood in 1958 British cohort: longitudinal study. BMJ 2001; 323: 1331-5.

[23] Catalano PM, Kirwan JP, Haugel-de Mouzon S, King J. Gestational diabetes and insulin resistance: role in short- and longterm implications for mother and fetus. J Nutr 2003; 133: 1674S1683 .

[24] Silverman BL, Rizzo TA, Cho NH, Metzger BE. Long-term effects of the intrauterine environment. Diabetes Care 1998; Suppl 2: B142-B149.

[25] Dabelea D, Hanson RL, Lindsay RS, et al. Intrauterine exposure to diabetes conveys risks for type 2 diabetes and obesity: a study of discordant sibships. Diabetes 2000; 49: 2208-11.

[26] Poretsky L, Cataldo NA, Rosenwaks Z, Giudice LC. The insulinrelated ovarian regulatory system in health and disease. Endocr Rev 1999; 20: 535-82.

[27] Slyper AH. The pediatric obesity epidemic: causes and controversies. J Clin Endocrinol Metab 2004; 89: 2540-7.

[28] Buyken AE, Karaolis-Danckert N, Remer T. Association of prepubertal body composition in healthy girls and boys with the timing of early and late pubertal markers. Am J Clin Nutr 2009; 89: 221-30.

[29] Kaplowitz PB, Rundle AC, Blethen SL. Weight relative to height before and during growth hormone therapy in prepubertal children. Horm Metab Res 1998; 30: 565-9.
[30] Wang Y. Is obesity associated with early sexual maturation? A comparison of the association in American boys versus girls. Pediatrics 2002; 110: 903-10.

[31] Hochberg Z. Evo-devo of child growth II: human life history and transition between its phases. Eur J Endocrinol 2009; 160: 135-41.

[32] Ralt D. The muscle--fat duel or why obese children are taller? BMC Pediatr 2006; 6: 33 .

[33] Buyken AE, Karaolis-Danckert N, Remer T. Association of prepubertal body composition in healthy girls and boys with the timing of early and late pubertal markers. Am J Clin Nutr 2009; 89: 221-30.

[34] Chen X, Wang Y. The influence of sexual maturation on blood pressure and body fatness in African-American adolescent girls and boys. Am J Hum Biol 2009; 21: 105-12.

[35] Rosenfield RL, Lipton RB, Drum ML. Thelarche, pubarche, and menarche attainment in children with normal and elevated body mass index. Pediatrics 2009; 123: 84-8.

[36] Mauras N, Rogol AD, Haymond MW, Veldhuis JD. Sex steroids, growth hormone, insulin-like growth factor-1: neuroendocrine and metabolic regulation in puberty. Horm Res 1996; 45: 74-80.

[37] Guercio G, Rivarola MA, Chaler E, Maceiras M, Belgorosky A. Relationship between the growth hormone/insulin-like growth factor-I axis, insulin sensitivity, and adrenal androgens in normal prepubertal and pubertal girls. J Clin Endocrinol Metab 2003; 88: 1389-93.

[38] Juul A, Dalgaard P, Blum WF, et al. Serum levels of insulin-like growth factor (IGF)-binding protein-3 (IGFBP-3) in healthy infants, children, and adolescents: the relation to IGF-I, IGF-II, IGFBP-1, IGFBP-2, age, sex, body mass index, and pubertal maturation. J Clin Endocrinol Metab 1995; 80: 2534-42.

[39] Juul A, Dalgaard P, Blum WF, et al. Serum levels of insulin-like growth factor (IGF)-binding protein-3 (IGFBP-3) in healthy infants, children, and adolescents: the relation to IGF-I, IGF-II, IGFBP-1, IGFBP-2, age, sex, body mass index, and pubertal maturation. J Clin Endocrinol Metab 1995; 80: 2534-42.

[40] Larnkjaer A, Ingstrup HK, Schack-Nielsen L, et al. Early programming of the IGF-I axis: negative association between IGF-I in infancy and late adolescence in a 17-year longitudinal follow-up study of healthy subjects. Growth Horm IGF Res 2009; 19: 82-6.

[41] Lofqvist C, Andersson E, Gelander L, et al. Reference values for insulin-like growth factor-binding protein-3 (IGFBP-3) and the ratio of insulin-like growth factor-I to IGFBP-3 throughout childhood and adolescence. J Clin Endocrinol Metab 2005; 90: 1420-7.

[42] Loomba-Albrecht LA, Styne DM. Effect of puberty on body composition. Curr Opin Endocrinol Diabetes Obes 2009; 16: 10-5.

[43] Ong KK, Langkamp M, Ranke MB, et al. Insulin-like growth factor I concentrations in infancy predict differential gains in body length and adiposity: the Cambridge Baby Growth Study. Am J Clin Nutr 2009; 90: 156-61.

[44] Lofqvist C, Andersson E, Gelander L, et al. Reference values for insulin-like growth factor-binding protein-3 (IGFBP-3) and the ratio of insulin-like growth factor-I to IGFBP-3 throughout childhood and adolescence. J Clin Endocrinol Metab 2005; 90: 1420-7.

[45] Juul A, Dalgaard P, Blum WF, et al. Serum levels of insulin-like growth factor (IGF)-binding protein-3 (IGFBP-3) in healthy infants, children, and adolescents: the relation to IGF-I, IGF-II, IGFBP-1, IGFBP-2, age, sex, body mass index, and pubertal maturation. J Clin Endocrinol Metab 1995; 80: 2534-42.

[46] Ong KK, Langkamp M, Ranke MB, et al. Insulin-like growth factor I concentrations in infancy predict differential gains in body length and adiposity: the Cambridge Baby Growth Study. Am J Clin Nutr 2009; 90: 156-61.

[47] Berthoud HR, Morrison C. The brain, appetite, and obesity. Annu Rev Psychol 2008; 59: 55-92.

[48] Nieuwenhuizen AG, Rutters F. The hypothalamic-pituitaryadrenal-axis in the regulation of energy balance. Physiol Behav 2008; 94: 169-77.

[49] Russell DR, McEwen BS. Stress and the Adolescent Brain. Ann N Y Acad Sci 2006; 1094: 202-14.

[50] Diamanti-Kandarakis E, Bourguignon JP, Giudice LC, et al. Endocrine-disrupting chemicals: an endocrine society scientific statement. Endocr Rev 2009; 30: 293-342. 
[51] DiDiego MLMRF, Eggert JAP, Pruitt RHP, Larcom LLP. Unmasking the truth: behind endocrine disruptors. [Miscellaneous]. Nurse Practitioner 2005; 30: 54-9.

[52] Wang RY, Needham LL, DB Barr. Effects of environmental agents on the attainment of puberty: considerations when assessing exposure to environmental chemicals in the national children's study. Environ Health Perspec 2005; 113: 1100-7.

[53] Chan JM, Wang F, Holly EA. Whole grains and risk of pancreatic cancer in a large population-based case-control study in the San Francisco Bay area, California. Am J Epidemiol 2007; 166: 117485.

[54] Greet S, Elly DH, Willem D, Nik van L, Marike L. Endocrine disruptors and abnormalities of pubertal development. Basic Clin Pharmacol Toxicol 2008; 102: 168-75.

[55] Chen JQ, Brown TR, Russo J. Regulation of energy metabolism pathways by estrogens and estrogenic chemicals and potential implications in obesity associated with increased exposure to endocrine disruptors. Biochimica et Biophysica Acta (BBA). Molecul Cell Res 2009; 1793: 1128-43.

[56] Elobeid MA, Allison DB. Putative environmental-endocrine disruptors and obesity: a review. [Miscellaneous]. Curr Opin Endocrinol Diabet Obes 2008; 15: 403-8.

[57] Grun F, Blumberg B. Endocrine disrupters as obesogens. Molecul Cell Endocrinol 2009; 304: 19-29.

[58] Keith SW, Redden DT, Katzmarzyk PT, et al. Putative contributors to the secular increase in obesity: exploring the roads less traveled. Int J Obes 2006; 30: 1585-94

[59] Spalding KL, Arner E, Westermark PO, et al. Dynamics of fat cell turnover in humans. Nature 2008; 453: 783-7.

[60] Nilsson R. Endocrine modulators in the food chain and environment. Toxicol Pathol 2000; 28: 420-31.

[61] LeVine RA. Human parental care: universal goals, cultural strategies, individual behavior. New Directions for Child and Adolesc Deve 1988; 40: 3-12.

[62] Spruijt-Metz D, Li C, Cohen E, Birch L, Goran M. Longitudinal influence of mother's child-feeding practices on adiposity in children. J Pediatr 2006; 148: 314-20.

[63] Spruijt-Metz D, Lindquist CH, Birch LL, Fisher JO, Goran MI. Relation between mothers' child-feeding practices and children's adiposity. Am J Clin Nutr 2002; 75: 581-6.

[64] Fisher JO, Birch LL. Eating in the absence of hunger and overweight in girls from 5 to $7 \mathrm{y}$ of age. Am J Clin Nutr 2002; 76: 226-31.

[65] Francis LA, Hofer SM, Birch LL. Predictors of maternal childfeeding style: maternal and child characteristics. Appetite 2001; 37: 231-43.

[66] Jennifer S. Savage JOFLLB. Parental influence on eating behavior: conception to adolescence. J Law Med Ethics 2007; 35: 22-34.

[67] Moens E, Braet C. Predictors of disinhibited eating in children with and without overweight. Behav Res Ther 2007; 45: 1357-68.

[68] Butte NF, Cai G, Cole SA, et al. Metabolic and behavioral predictors of weight gain in Hispanic children: the Viva la Familia Study. Am J Clin Nutr 2007; 85: 1478-85

[69] Casey R, Rozin P. Changing children's food preferences: parent opinions. Appetite 1989; 12: 171-82.

[70] Birch LL, Zimmerman S, Hind H. The influences of socialaffective context on preschool children's food preferences. Child Dev 1980; 51: 856-61.

[71] Eric Stice. Risk and maintenance factors for eating pathology: A meta-analytic review. Psychol Bull 2002; 128: 825-48.

[72] Braet C, Claus L, Goossens L, Moens E, Van Vlierberghe L, Soetens B. Differences in eating style between overweight and normal-weight youngsters. J Health Psychol 2008; 13: 733-43.

[73] Huon GF. Dieting, binge eating, and some of their correlates among secondary school girls. Int J Eat Disord 1994; 15: 159-64.

[74] Galloway AT, Fiorito L, Lee Y, Birch LL. Parental pressure, dietary patterns, and weight status among girls who are "Picky Eaters". J Am Diet Assoc 2005; 105: 541-8.

[75] Galloway AT, Fiorito LM, Francis LA, Birch LL. 'Finish your soup': Counterproductive effects of pressuring children to eat on intake and affect. Appetite 2006; 46: 318-23.

[76] Robert Batsell W, Brown AS, Ansfield ME, Paschall GY. "You Will Eat All of That!": A retrospective analysis of forced consumption episodes. Appetite 2002; 38: 211-9.
[77] Ogden CL, Carroll MD, Curtin LR, McDowell MA, Tabak CJ, Flegal KM. Prevalence of overweight and obesity in the united states, 1999-2004. JAMA 2006; 295: 1549-55.

[78] Papas MA, Alberg AJ, Ewing R, Helzlsouer KJ, Gary TL, Klassen AC. The built environment and obesity. Epidemiol Rev 2007; 29: $129-43$.

[79] Dubowitz T, Heron M, Bird CE, et al. Neighborhood socioeconomic status and fruit and vegetable intake among whites, blacks, and Mexican Americans in the United States. Am J Clin Nutr 2008; 87: 1883-91

[80] Merchant AT, Dehghan M, Behnke-Cook D, Anand SS. Diet, physical activity, and adiposity in children in poor and rich neighbourhoods: a cross-sectional comparison. Nutr J 2007; 6: 1 .

[81] Wang MC, Kim S, Gonzalez AA, MacLeod KE, Winkleby MA. Socioeconomic and food-related physical characteristics of the neighbourhood environment are associated with body mass index. J Epidemiol Community Health 2007; 61: 491-8.

[82] Alaimo K, Olson CM, Frongillo EA, Jr. Low family income and food insufficiency in relation to overweight in US children: is there a paradox? Arch Pediatr Adolesc Med 2001; 155: 1161-7.

[83] Dinour LM, Bergen D, Yeh MC. The food insecurity-obesity paradox: a review of the literature and the role food stamps may play. J Am Diet Assoc 2007; 107: 1952-61.

[84] Trevino RP, Fogt DL, Wyatt TJ, et al. Diabetes risk, low fitness, and energy insufficiency levels among children from poor families. J Am Diet Assoc 2008; 108: 1846-53.

[85] Veugelers P, Sithole F, Zhang S, Muhajarine N. Neighborhood characteristics in relation to diet, physical activity and overweight of Canadian children. Int J Pediatr Obes 2008: 1-8.

[86] Videon TM, Manning CK. Influences on adolescent eating patterns: the importance of family meals. J Adolesc Health 2003; 32: $365-73$

[87] Zenk SN, Schulz AJ, Hollis-Neely T, et al. Fruit and vegetable intake in African Americans income and store characteristics. Am J Prev Med 2005; 29: 1-9.

[88] Cummins S, Macintyre S. Food environments and obesity-neighbourhood or nation? Int J Epidemiol 2006; 35: 100-4.

[89] Stimpson JP, Nash AC, Ju H, Eschbach K. Neighborhood Deprivation is associated with lower levels of serum carotenoids among adults participating in the Third National Health and Nutrition Examination Survey. J Am Diet Assoc 2007; 107: 1895902.

[90] Cummins S, Macintyre S. Food environments and obesity-neighbourhood or nation? Int J Epidemiol 2006; 35: 100-4.

[91] Moore LV, ez Roux AV. Associations of neighborhood characteristics with the location and type of food stores. Am J Public Health 2006; 96: 325-31.

[92] Veugelers P, Sithole F, Zhang S, Muhajarine N. Neighborhood characteristics in relation to diet, physical activity and overweight of Canadian children. Int J Pediatr Obes 2008; 3(3): 152-9.

[93] Powell LM, Auld MC, Chaloupka FJ, O'Malley PM, Johnston LD. Associations between access to food stores and adolescent body mass index. Am J Prev Med 2007; 33: S301-S307.

[94] Powell LM, Auld MC, Chaloupka FJ, O'Malley PM, Johnston LD. Associations between access to food stores and adolescent body mass index. Am J Prev Med 2007; 33: S301-S307.

[95] Davis B, Carpenter C. Proximity of fast-food restaurants to schools and adolescent obesity. Am J Public Health 2009; 99: 505-10.

[96] Powell LM, Auld MC, Chaloupka FJ, O'Malley PM, Johnston LD. Associations between access to food stores and adolescent body mass index. Am J Prev Med 2007; 33: S301-S307.

[97] Veugelers P, Sithole F, Zhang S, Muhajarine N. Neighborhood characteristics in relation to diet, physical activity and overweigh of Canadian children. Int J Pediatr Obes 2008: 1-8 [Epub ahead of print].

[98] Moore LV, ez Roux AV. Associations of neighborhood characteristics with the location and type of food stores. Am J Public Health 2006; 96: 325-31.

[99] Stimpson JP, Nash AC, Ju H, Eschbach K. Neighborhood Deprivation is associated with lower levels of serum carotenoids among adults participating in the Third National Health and Nutrition Examination Survey. J Am Diet Assoc 2007; 107: 1895902.

[100] Zenk SN, Schulz AJ, Hollis-Neely T, et al. Fruit and vegetable intake in African Americans income and store characteristics. Am J Prev Med 2005; 29: 1-9. 
[101] Dunton GF, Kaplan J, Wolch J, Jerrett M, Reynolds KD. Physical environmental correlates of childhood obesity: a systematic review. Obes Rev 2009; 10: 393-402.

[102] Boardman JD, Saint Onge JM, Rogers RG, Denney JT. Race differentials in obesity: the impact of place. J Health Soc Behav 2005; 46: 229-43.

[103] Andrea J Romero. Low-income neighborhood barriers and resources for adolescents' physical activity. J Adolesc Health 2005; 36: $253-9$.

[104] Evenson KR, Scott MM, Cohen DA, Voorhees CC. Girls' perception of neighborhood factors on physical activity, sedentary behavior, and BMI. Obesity (Silver Spring) 2007; 15: 430-45.

[105] Chen E, Paterson LQ. Neighborhood, family, and subjective socioeconomic status: How do they relate to adolescent health? Health Psychol 2006; 25: 704-14.

[106] Franzini L, Elliott MN, Cuccaro P, et al. Influences of physical and social neighborhood environments on children's physical activity and obesity. Am J Public Health 2009; 99: 271-8

[107] Lumeng JC, Appugliese D, Cabral HJ, Bradley RH, Zuckerman B. Neighborhood safety and overweight status in children. Arch Pediatr Adolesc Med 2006; 160: 25-31.
[108] Veugelers P, Sithole F, Zhang S, Muhajarine N. Neighborhood characteristics in relation to diet, physical activity and overweight of Canadian children. Int J Pediatr Obes 2008: 1-8.

[109] Burdette HL, Whitaker RC. Neighborhood playgrounds, fast food restaurants, and crime: relationships to overweight in low-income preschool children. Prev Med 2004; 38: 57-63.

[110] Whitaker RC, Orzol SM. Obesity among US urban preschool children: relationships to race, ethnicity, and socioeconomic status. Arch Pediatr Adolesc Med 2006; 160: 578-84.

[111] Plagemann A. A matter of insulin: developmental programming of body weight regulation. J Matern Fetal Neonatal Med 2008; 21: 143-8.

[112] Dubowitz T, Heron M, Bird CE, et al. Neighborhood socioeconomic status and fruit and vegetable intake among whites, blacks, and Mexican Americans in the United States. Am J Clin Nutr 2008; 87: 1883-91.

[113] Wang MC, Kim S, Gonzalez AA, MacLeod KE, Winkleby MA. Socioeconomic and food-related physical characteristics of the neighbourhood environment are associated with body mass index. J Epidemiol Commun Health 2007; 61: 491-8.

(C) Cardel et al.; Licensee Bentham Open.

This is an open access article licensed under the terms of the Creative Commons Attribution Non-Commercial License (http: //creativecommons.org/licenses/by$\mathrm{nc} / 3.0 /$ ), which permits unrestricted, non-commercial use, distribution and reproduction in any medium, provided the work is properly cited. 